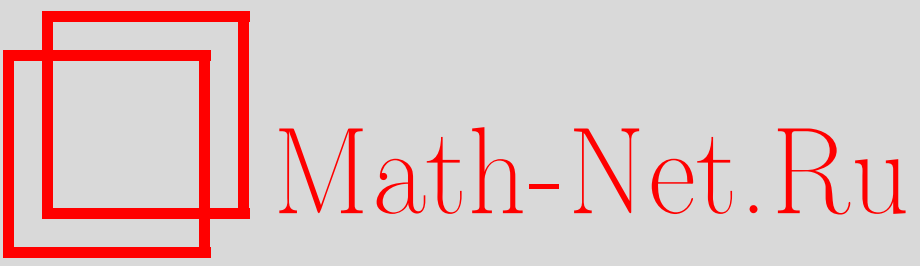

А. А. Афиногентов, Моделирование процесса деформации металлических заготовок цилиндрической формы, Вестн. Сам. гос. техн. ун-та. Сер. Физ.-мат. науки, 2007, выпуск 2(), 170-172

DOI: https://doi.org/10.14498/vsgtu551

Использование Общероссийского математического портала Math-Net.Ru подразумевает, что вы прочитали и согласны с пользовательским соглашением http://www.mathnet.ru/rus/agreement

Параметры загрузки:

IP : 3.85 .183 .62

26 апреля 2023 г., 17:35:59 
Вестн. Сам. гос. техн. ун-та. Сер.: Физ.-мат. науки. - 2007. - № 2(15). - С. 170-172. - ISSN 1991-8615

\section{УДК 681.5}

\section{А. А. Афиногентов}

\section{МОДЕЛИРОВАНИЕ ПРОЦЕССА ДЕФОРМАЦИИ МЕТАЛЛИЧЕСКИХ ЗАГОТОВОК ЦИЛИНДРИЧЕСКОЙ ФОРМЫ}

Полученъ бункииональные зависимости, определяюшие взаимосвязъ между температурой пластической зоны и основныли технологическими параметрами в прочессе прессования заготовок ијлиндрической бормы на горизонталъных гидравлических прессах.

Принципиальная особенность системного подхода к математическому моделированию процесса нагрева деталей и их последующей пластической деформации заключается в рассмотрении цепочки взаимосвязанных технологических стадий обработки металлических изделий (нагрев, транспортировка, обработка давлением) как единого технологического комплекса, рассматриваемого в качестве объекта управления. В настоящей работе рассматривается с указанных позиций задача моделирования процесса прессования заготовок цилиндрической фрормы на горизонтальных гидравлических прессах после их предварительного нагрева в индукционных печах.

Конечным продуктом технологического комплекса «печь- пресс» является пресс-изделие требуемой длины $h^{*}$. Процесс прессования является заключительной стадией технологического цикла, влияющей на температурное поле изделия.

В условиях осесимметричной деформации температурное поле $T(r, l, \tau)$ может быть описано двумерным нестационарным уравнение теплопроводности в цилиндрических координатах:

$$
\frac{\partial T}{\partial \tau}=a\left[\frac{\partial^{2} T}{\partial r^{2}}+\frac{\partial^{2} T}{\partial l^{2}}+\frac{1}{r} \frac{\partial T}{\partial r}\right]-V_{l} \frac{\partial T}{\partial l}-V_{r} \frac{\partial T}{\partial r}+\frac{W^{*}}{c \rho},
$$

где $\tau$ - время; $V_{r}\left(r, l, V_{0}\right)$ и $V_{l}\left(r, l, V_{0}\right)$ - соответственно радиальная и продольная составляющее вектора скорости течения прессуемого металла, каждая из которых является фрунцией радиальной $r$ и продольной $l$ (в направлении прессования) координат, а также скорости прессования $V_{0} ; \rho, c$ и $a$ - плотность, коэффициенты теплопроводности и температуропроводности соответственно; $W^{*}\left(r, l, V_{r}, V_{l}\right)$ - объёмная плотность внутренних источников тепла, определяемых энергией пластического формоизменения согласно выражению

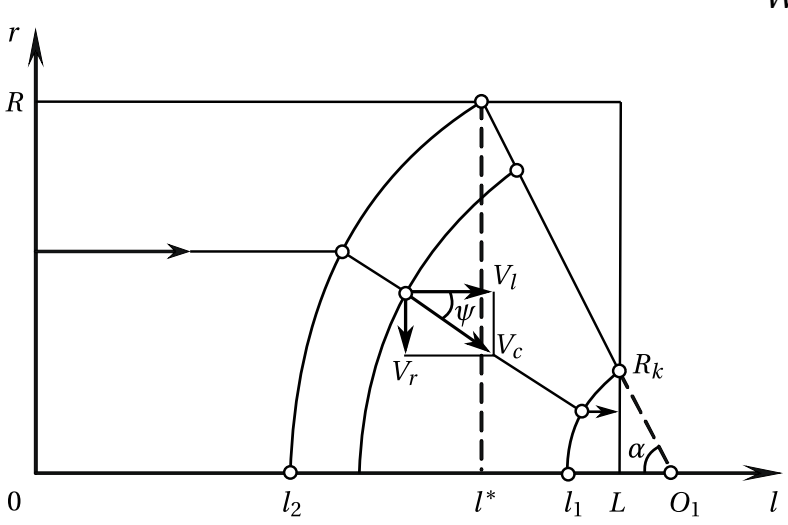

Рис. 1. Поле скоростей течения металла

$$
W^{*}=Q H \text {, }
$$

где $Q$ - интенсивность касательных напряжений при пластической деформации, $H$ - интенсивность скоростей деформации сдвига.

В целях изучения температурного поля можно использовать (в условиях осесимметричной деформации) упрощённые представления о поле скоростей, основанные на гипотезе сорерических сечений [1].

На рис. 1 в плоскости координат $r$ и $l(r-$ радиус заготовки, $l$ - длина заготовки) изображена область течения металла, границы которой определяются радиусом слитка $R$, радиусом пресс-изделия $R_{k}$ и углом $\alpha>0$, учитывающим существование упругой зоны при прессовании. Примем, что в пределах обжимающей части пластической зоны (ОЧПЗ) скорости течения $V_{c}$ постоянны на концентрических сорерах радиусом $R_{c}$ с центром в точке $O_{1}$ и направлены к этой точке, а за пределами ОЧПЗ $V=V_{l}=V_{0}$ при $0<l<l^{*}$ и $V=V_{l}=V_{0}\left(\frac{R}{R_{k}}\right)^{2}$ при $l_{1} \leqslant l \leqslant L$.

Тогда, принимая за торцевые поверхности ОЧПЗ сореры радиусом соответственно $R_{\max }=\frac{R}{\sin \alpha}$ и $R_{\min }=\frac{R_{k}}{\sin \alpha}$, имея в виду условие неразрывности деформируемой среды, получим

$$
V_{c}=V_{0}\left(\frac{R}{R_{c} \sin \alpha}\right)^{2} .
$$


Процесс прессования сопровождается непрерывным перемещением заготовки относительно матрицы, что можно интерпретировать как непрерывное перемещение концентрических сфер, ограничивающих области деформации (рис. 2).

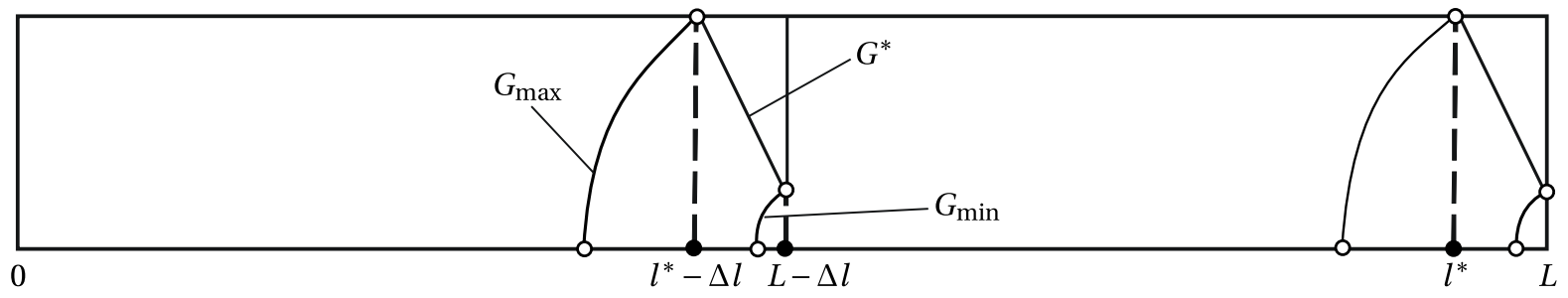

Рис. 2. Изменение положения областей деформации

Очевидно, что при прессовании с постоянной скоростью $V_{0}$ изменение координаты можно найти как $\Delta l=V_{0} \tau$, где $\tau$ - произвольный момент времени. Тогда, учитывая пространственное изменение координат областей деформации, на основе простых аналитических выражений приведённых в [2,3], получим следующие расчётные формулы в абсолютных единицах для произвольного момента времени $\tau$ :

$$
\begin{gathered}
G^{*}=R-\frac{l+V_{0} \tau-l^{*}}{\operatorname{tg}\left(\frac{\pi}{2}-\alpha\right)}, \\
G_{\max }=R_{\max } \sin \left(\arccos \left(\frac{l+V_{0} \tau-L-O_{1}}{R_{\max }}\right)\right), \\
G_{\min }=R_{\min } \sin \left(\arccos \left(\frac{l+V_{0} \tau-L-O_{1}}{R_{\min }}\right)\right) .
\end{gathered}
$$

Тогда из объединения условий $G_{\min }<r<G_{\max }$ и $r<G^{*}$ определяются границы ОЧПЗ: $l_{2}-\Delta l<$ $<l<L-\Delta l$, поле скоростей в которой определяется следующим образом:

$$
\begin{gathered}
V_{l}=V_{c} \cos \psi=\frac{V_{0}\left(R_{k}+\left(L-l-V_{0} \tau\right) \operatorname{tg} \alpha\right)}{R v \sqrt{v} \cos ^{2} \alpha}, \\
V_{r}=-V_{c} \sin \psi=\frac{-V_{0} r \operatorname{tg} \alpha}{R v \sqrt{v} \cos ^{2} \alpha}, \\
v=\left(\frac{r}{R}\right)^{2} \operatorname{tg}^{2} \alpha+\left(\frac{R_{k}+L-l-V_{0} \cdot \tau}{R} \cdot \operatorname{tg} \alpha\right)^{2} .
\end{gathered}
$$

В пределах упругой зоны, т. е. при $r>G^{*}$, при $y^{*}-\Delta y<y<l-\Delta y$ имеем:

$$
V_{r}=V_{l}=0 .
$$

Координаты точек $l^{*}$ и $O_{1}$ определяется так:

$$
\begin{gathered}
l^{*}=L-\frac{R-R_{k}}{\operatorname{tg} \alpha}, \\
O_{1}=\frac{R_{k}}{\operatorname{tg} \alpha} .
\end{gathered}
$$

Согласно [4] интенсивность скоростей деформации сдвига определяется соотношением

$$
H=\sqrt{2\left[\left(\frac{\partial V_{r}}{\partial r}\right)^{2}+\left(\frac{\partial V_{l}}{\partial l}\right)^{2}+\left(\frac{V_{r}}{r}\right)^{2}+\frac{1}{2}\left(\frac{\partial V_{l}}{\partial r}+\frac{\partial V_{r}}{\partial l}\right)^{2}\right]} .
$$

Подставляя в (13) соответствующие значения скоростей (7) и (8), получим:

$$
W^{*}=\frac{V_{0} Q_{0}}{R v \sqrt{v} \cos ^{2} \alpha} \omega(r, y),
$$


где $\omega(r, y)=1$ или $\omega(r, y)=0$ в зависимости от расположения точки $(r, l)$, а именно внутри или за пределами ОЧПЗ.

В [3] показано, что интенсивность касательных напряжений при пластической деформации может быть аппроксимирована линейной температурной зависимостью вида

$$
Q(T)=Q_{0}-\zeta T .
$$

Тепловой поток контактного трения $q$ в первом приближении можно представить следующим образом:

$$
q(l)=\left\{\begin{array}{cc}
k_{q} V_{0}, & \forall l \in\left[0, l^{*}\right], \\
0, & \forall l \in\left[l^{*}, L\right] .
\end{array}\right.
$$

Здесь постоянные $\zeta$ и $k_{q}-$ коэфрфициенты пропорциональности, $Q_{0}-$ значение мощности внутренних источников тепла пластической деформации при нулевой температуре.

Пространственное распределение поля скоростей течения металла в зоне деформации (рис. 3 и 4 ) определяет фрункцию распределения внутренних источников тепла пластического фрормоизменения металла (см. рис. 5). В периферийных областях скорости течения металла минимальны. Максимальные скорости течения металла достигаются на выходе из зоны деформации в канале матрицы и соответствуют наибольшей интенсивности тепловыделения, следовательно распределение источников тепла пластической дефрормации обуславливает максимальный прирост температуры на выходе из очага деформации.

Таким образом, в упрощённом виде сорормулирована математическая модель процесса прессования. Выражения (1)-(16) определяют взаимосвязь температуры $T$, вектора скоростей деформации $V=\left\{V_{r}, V_{l}\right\}$, и фрункции $W^{*}$ распределения внутренних источников тепла, образуемых при пластическом формоизменении металла.

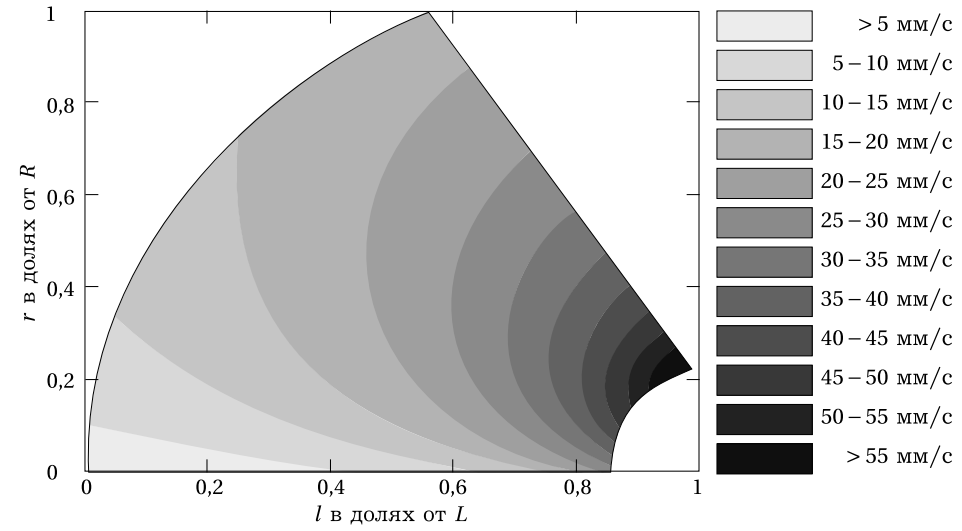

Рис. 3. Радиальная составляющая скорости течения металла

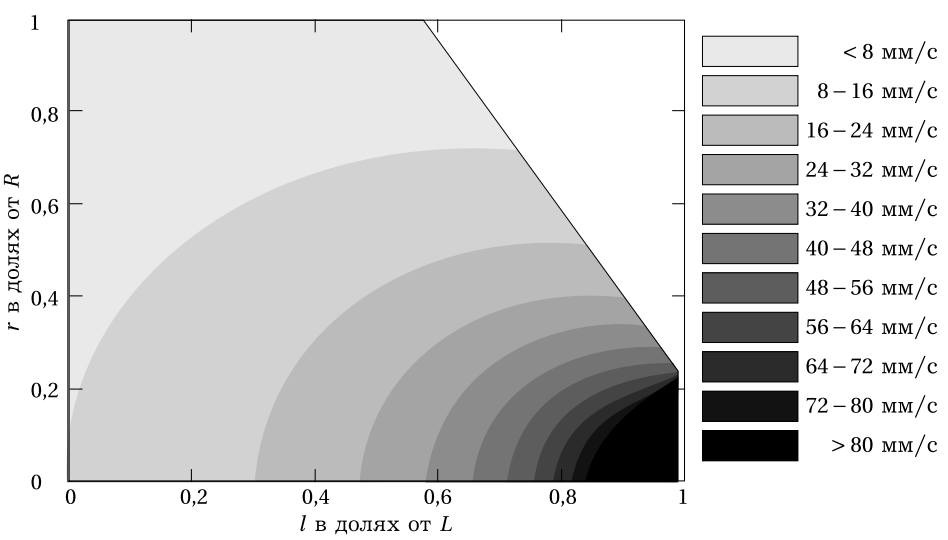

Рис. 4. Продольная составляющая скорости течения металла

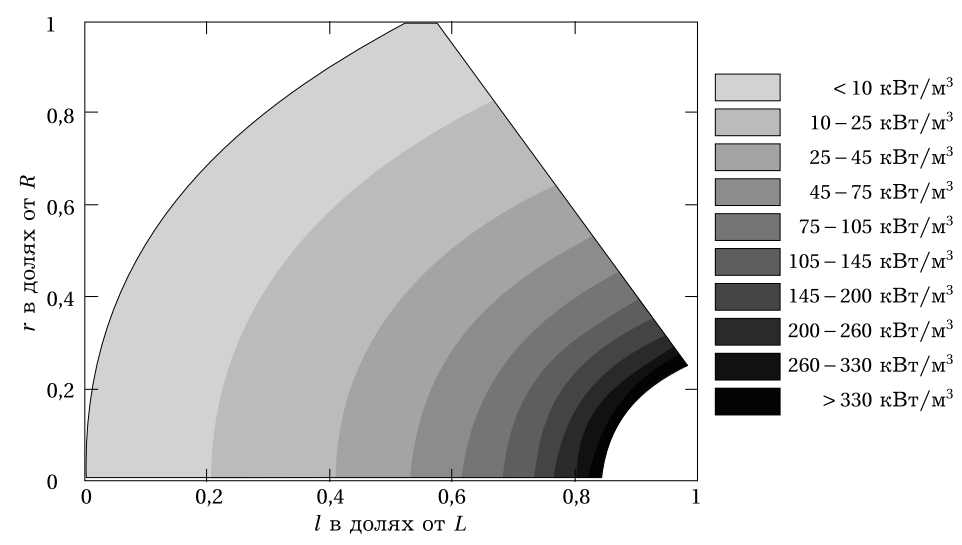

Рис. 5. Распределение внутренних источников тепла пластической деформации

\section{БИБЛИОГРАФИЧЕСКИЙ СПИСОК}

1. Перлин, И.Л. Теория прессования металлов [Текст] / И. Л. Перлин, Л. Х. Гайтбарг. - М.: Металлургия, 1975. $448 \mathrm{c.}$

2. Рапопорт, Э.Я. Оптимизация процессов индукционного нагрева металла [Текст] / Э. Я. Рапопорт. - М.: Металлургия, 1993. -279 с.

3. Рапопорт, Э.Я. Математическое моделирование температурных полей деформируемого металла в процессе прессования [Текст] / Э. Я. Рапопорт // Физика и химия обработки материалов. - 1980. - № 1. - C. $29-39$.

4. Гун, Г.Я. Математическое моделирование процессов обработки металлов давлением [Текст] / Г. Я. Гун. - М.: Металлургия, 1983. - 352 с. 